\title{
Increased Scrutiny of Medical Websites
}

\section{Mark B. Langdon, Esq}

The growing number of Web sites that offer consumers the opportunity to obtain prescription medications have recently been attracting considerable regulatory scrutiny from federal and state health officials.

On December 28, 1999, President Clinton announced a $\$ 10$ million initiative aimed at cracking down on illegal sales of prescription drugs over the Internet. The proposal would protect consumers from illegitimate Internet pharmacies that inappropriately prescribe medications, increase the risk of dangerous drug interactions, or sell potentially counterfeited or contaminated drugs. The proposal comes on the heels of Congressional hearings that were held on this subject late last year. The Clinton plan would allow the Food and Drug Administration (FDA) to start verifying the quality of hundreds of online companies that have emerged in the last year. Many of these companies allow consumers to fill prescriptions without going to a traditional drugstore. In addition, some of these sites allow consumers to obtain prescription medication merely by filling out an online questionnaire.

If approved by Congress, the administration's proposal would create federal fines of up to $\$ 500,000$ for e-pharmacies that dispense drugs without first obtaining a valid prescription from the buyer. The proposal also would give the FDA new investigative authority through administrative subpoena, which the agency currently lacks. The initiative provides that the FDA will carry out a public education campaign on safe ways to purchase pharmaceuticals over the Internet. The FDA will enable consumers to identify legitimate Internet pharmacy sites that operate consistently with state and federal law. FDA would use part of the budget increase to develop a rapid response

The above Health Law article is reprinted with permission from Health Law Trends, Spring, 2000, a publication of Washington Law Firm of Arent Fox Klintner Plotkin and Kahn, PLLC. Address correspondence: Mark B. Langdon, Esq, at Arent Fox, PLLC, 1050 Connecticut Avenue, Washington, DC 20036 team and upgrade the FDA's computer technology to identify, investigate, and prosecute illegitimate Internet pharmacies.

The initiative represents the government's first attempt to regulate the growing e-health industry, and is significant because states are often powerless to bring enforcement actions against providers who are licensed in multiple states. However, since protecting the health of residents is a duty traditionally delegated to the states, the proposal is likely to generate controversy.

The FDA announced February 2 that it has sent electronic letters to at least a dozen foreign Web sites, warning them that their prescription drug sales to U.S. citizens potentially are illegal. This marks the first time the agency has sent warning letters over the Internet. The FDA said it may start using electronic warning letters to curtail illegal sales of prescription drugs from U.S.-based Web sites. The FDA seeks to at least cut in half the current number of illicit domestic sites.

The Clinton proposal comes after state attorneys general and pharmaceutical companies have pledged steps against online pharmacy fraud. Attorneys general from several states have taken action against online drugstores, charging some of them with being unlicensed and unregistered to do business in their states. In addition, several state medical boards have fined physicians and suspended their licenses for prescribing and dispensing medications to patients they have never seen.

In Kansas, the Attorney General last year filed civil petitions alleging violations of consumer protection laws against seven companies that were selling prescriptiononly medications, including Viagra and weight-loss drugs, over the Internet. The Attorney General alleged that prescription drugs were dispensed by a doctor or pharmacist who was not licensed in the state. The state went after not only the sites that prescribe the medications, but also three pharmacies that filled the prescriptions. If found liable, the companies could face penalties of $\$ 5,000$ to $\$ 10,000$ per violation. 
In November 1999, a Missouri judge, responding to a suit brought by Attorney General Jeremiah W. "Jay" Nixon, issued a permanent injunction blocking an online Texasbased pharmacy and other defendants from engaging in the unlawful sale of prescription-only drugs to Missourians over the Internet. The pharmacy paid a fine of $\$ 15,000$, lawsuit costs, and restitution to Missouri residents. In response to a separate action brought by Nixon, the court issued a permanent injunction in October blocking a San Antonio, Texas-based pharmacy operator from filling or shipping prescriptions over www.thepillbox.com and required the defendants to pay $\$ 15,000$ in penalties and costs to the state.

In October 1999, Illinois Attorney General Jim Ryan filed four lawsuits against out-of-state Internet pharmacies and their physicians and operators, alleging that they were not licensed and registered to do business in the state. An Illinois physician was also fined by the State Board of Medicine $\$ 1,000$ and placed on probation for two years for unprofessional conduct.

In December 1999, the Michigan Attorney General issued warnings to 10 online pharmacies for selling drugs to Michigan residents over the Internet. The suits allege violations of the state Consumer Protection Act, which carries a maximum penalty of $\$ 25,000$ per violation.

Enforcement actions have also recently been taken against Internet physicians and/or pharmacies in California, Ohio, Maryland, Colorado, Washington, Wisconsin, Wyoming, and Arizona. Further, there are at least 19 states that are expected to consider legislation regulating the sale of online prescription drugs.

In addition to these recent state enforcement activities, the American Medical Association (AMA) recently took the position that online physicians who write prescriptions without patient contact are in direct violation of AMA policy. At its convention last summer, the AMA called on state medical societies, government regulators, and licensing boards to investigate doctors who dispense pills to patients without examining them. Noting that no state laws directly address the issue of online prescribing, the AMA said that it would assist the Federation of State Medical Boards (FSMB) in developing them. But in the absence of state law, the AMA says that local medical boards should take action against doctors who are prescribing drugs for patients they do not know. The AMA
Board of Trustees report, which was adopted by the House of Delegates, directs the AMA to work with the FSMB, the National Association of Boards of Pharmacy, and the Food and Drug Administration to curtail inappropriate online prescribing. Nevertheless, the report did recognize the growing use of the Internet in health care, and states that online transmission of prescriptions, order refills, and electronic consults may be appropriate if the physician and patient have a preexisting relationship.

The National Association of Boards of Pharmacy (NABP), which represents state pharmaceutical licensing authorities, has also taken the position that any site that uses a questionnaire without a legitimate patient-physician relationship is illegal. To help guide consumers, the pharmacy association developed a voluntary seal program called the NABP Verified Internet Pharmacy Practice Sites (VIPPS) which endorses sites that meet its criteria for dispensing drugs online. The VIPPS seal certifies that an online pharmacy is licensed by the appropriate state boards of pharmacy to dispense pharmaceuticals. To receive the VIPPS seal, sites must meet criteria involving licensure, information, communication, storage and shipment, overthe-counter products, and quality improvement programs. To date, only four sites have received VIPPS accreditation: cvs.com, drugstore.com, Merck-Medco.com, and PlanetRx.com.

As more and more consumers turn to the Internet as a cost-effective and convenient way to obtain medical information and fill prescriptions, federal and state officials will continue to scrutinize the growing number of Internet drugstores and doctors offices to ensure that consumers are adequately protected. The sites that are presently attracting the most attention from the FDA and state attorneys general are those that sell misbranded or adulterated drugs, those that do not require a physical examination of the patient by a physician prior to prescribing, and those that are not appropriately licensed. Additional issues that will likely face medical Web sites include: the effect of state confidentiality laws and the newly-proposed federal privacy regulations on the confidentiality of patient information; the effect of federal and state fraud and abuse laws on the financial arrangements involving Web sites, their contracted pharmacies and physicians, and providers (such as pharmaceutical manufacturers) who advertise on the site; and the effect of state and federal consumer protection and advertising regulations. 